\title{
Grupos de pesquisa sobre infância, criança e educação infantil no Brasil: primeiras aproximações
}

\author{
Isabel de Oliveira e Silva, Iza Rodrigues da Luz, \\ Luciano Mendes de Faria Filho \\ Universidade Federal de Minas Gerais, Faculdade de Educação
}

\section{Introdução}

O objetivo deste artigo é apresentar um mapeamento dos grupos e instituições da área da educação que em 2008 produziam pesquisas sobre a infância, a criança e a educação infantil. Abrange os grupos de pesquisa, os pesquisadores e os projetos de pesquisa da área da educação que tomaram por tema explicitamente a infância, a criança ou a educação infantil no Brasil. Apresenta também uma aproximação aos temas de pesquisa evidenciados nas descrições desses grupos, procurando identificar tanto as permanências quanto possíveis temas emergentes.

A pesquisa que deu origem a este artigo foi realizada a partir de demanda formulada pelo Grupo de Trabalho Educação da Criança de 0 a 6 anos da ANPEd. ${ }^{1}$

${ }^{1}$ Os resultados da pesquisa foram apresentados, como trabalho encomendado, na 31를 Reunião Anual da ANPEd, em 2008. Agradecemos as contribuições dos pesquisadores e das pesquisadoras que participaram do debate após a apresentação, as quais foram consideradas para a redação do presente artigo.
Pretendia-se conhecer a distribuição geográfica, os temas de pesquisa e os pesquisadores que se dedicavam à temática no Brasil. Destaca-se que o trabalho não teve como objetivo oferecer o estado da arte sobre a pesquisa em educação infantil, pois as fontes foram os dados dos grupos de pesquisa e de seus líderes, o que não encerra a complexidade da área.

A educação da criança de 0 a 6 anos de idade configura-se como uma área de recente institucionalização no campo da educação e, embora se possa identificar o aumento do número de pesquisas e trabalhos relativos a essa etapa da educação básica, ela ainda é pouco representada no conjunto da produção acadêmica na pós-graduação brasileira. Ao estudar a produção de pesquisas na área da educação infantil no período 1983 a 1998, Strenzel (2000) identificou que a produção se concentrou-se no nível de mestrado ao longo da década de 1990, logrando crescimento significativo em relação às décadas anteriores. $\mathrm{O}$ crescimento do número de teses de doutorado verificou-se mais ao final do período analisado pela autora. Entendemos que a construção da área como campo de conhecimentos e seu fortalecimento no 
campo da educação passam também pela pesquisa institucionalizada. As transformações que vêm ocorrendo na última década no campo da pesquisa em educação no Brasil indicam a tendência de que, ao lado da pós-graduação stricto sensu, os grupos ou núcleos de pesquisa se constituem em espaços que promovem o avanço do conhecimento na área e a conformam, reunindo seus pesquisadores, elegendo temas, abordagens teórico-metodológicas, interfaces etc. Nessa direção, o maior conhecimento dos grupos e núcleos de pesquisa que se dedicam às questões da infância, da criança e da educação infantil configurase como importante estratégia de compreensão dessa área de estudos e pesquisas.

Ao assumirmos a tarefa de realizar este estudo, vimos que existem trabalhos que se dedicaram à análise da construção da área da educação infantil, voltados para a reflexão sobre os temas e abordagens predominantes, bem como para as tensões que a produção bibliográfica evidenciava (Campos \& Haddad, 1992; Rocha, 2008; Strenzel, 2000; Silva, 2008, dentre outros). No entanto, não localizamos trabalhos que tomassem como objeto os grupos de pesquisa, o que se deve possivelmente ao caráter recente e ainda em consolidação dessa forma de organização do trabalho científico no Brasil, especialmente nas ciências humanas. Dessa forma, este trabalho se configura como uma primeira aproximação a esse objeto - grupos de pesquisa -, o que o caracteriza como um estudo exploratório que pode contribuir inclusive para as análises dessa forma de organização da produção científica na área da educação e da educação infantil, bem como das formas de registro e de acesso à produção hoje existentes. ${ }^{2}$

Quanto à abrangência temática, buscamos incluir não apenas a educação infantil e os temas diretamente relacionados a essa etapa da educação básica, mas identificar também os grupos e pesquisadores que se

${ }^{2}$ Entendemos a relevância da reflexão sobre as condições institucionais de produção científica e as especificidades das áreas e subáreas de conhecimento, o que não seria possível nos limites deste trabalho. dedicavam ao estudo e à pesquisa das questões sobre a infância e sobre as crianças, não nos restringindo às abordagens voltadas para a faixa etária de 0 a 6 anos de idade. No entanto, procuramos destacar os dados relativos aos grupos e pesquisadores que se dedicam à educação infantil. Essa opção se justifica, por um lado, por acreditarmos que o conhecimento das crianças no contexto institucional da educação infantil é uma dimensão da problemática mais ampla da infância e demais questões decorrentes, como as relações intergeracionais, questões político-institucionais, o desenvolvimento humano, a participação na cultura e na vida social em geral. Por outro lado, a restrição à faixa etária de 0 a 6 anos poderia implicar deixar de fora grupos e pesquisadores cujas produções contribuem para o avanço do conhecimento na área, mas não se identificam por meio de descritores relativos à educação infantil.

\section{O processo da pesquisa}

Trata-se de uma pesquisa que pretende oferecer, do ponto de vista quantitativo, elementos para a compreensão do processo de constituição da área dos estudos sobre a infầncia, a criança e a educação infantil no campo da educação por meio do mapeamento dos grupos de pesquisa que investigam essa temática. Para isso, recorremos às bases de dados das agências que regulam e fomentam a pesquisa acadêmica no Brasil. Embora reconheçamos suas limitações para informar a respeito de toda a pesquisa desenvolvida nas diferentes áreas do conhecimento, entendemos que seus registros evidenciam a pesquisa institucionalizada, inscrevendo-se, então, as análises aqui contidas dentro desse limite. ${ }^{3}$

Para a delimitação do universo da pesquisa, definimos que inicialmente trabalharíamos com os grupos de pesquisa registrados no Diretório de Gru-

${ }^{3}$ A pertinência da análise dos dados da base Lattes para a compreensão da configuração da pesquisa em determinada área pode ser observada, dentre outros, no trabalho de Sobral; Almeida e Caixeta (2008). 
pos de Pesquisas do Conselho Nacional de Desenvolvimento Científico e Tecnológico ( $\mathrm{CNPq}$ - Base Corrente e Censo de Grupos de Pesquisa, 2006). Definimos também que, para o caso das informações sobre os pesquisadores, utilizaríamos a Plataforma Lattes da mesma agência. Com o intuito de perceber o quanto as pesquisas da área estão vinculadas (ou não) aos programas de pós-graduação em educação, identificamos o número de linhas e de projetos de pesquisas registrados que poderiam ser identificados por meio dos descritores definidos. Para isto, utilizamos os documentos disponibilizados pela Coordenação de Aperfeiçoamento de Pessoal de Nível Superior (CAPES) a respeito da avaliação (Caderno de Indicadores dos Programas de Pós-Graduação em Educação relativos ao ano de 2006 e Planilhas Comparativas da Avaliação Trienal 2007). Cumpre observar que tanto a Base Corrente de Grupos de Pesquisa quanto a Plataforma Lattes sofrem constantes alterações introduzidas pelos pesquisadores no que diz respeito aos grupos de pesquisa e aos currículos dos pesquisadores.

A busca por tais bases do CNPq e da CAPES justifica-se por sua importância, embora não exclusiva, a respeito da pesquisa institucionalizada. Além de revelar a maior ou menor consolidação da área como área de pesquisa reconhecida no campo da educação, permite também o cruzamento de dados a respeito das linhas e projetos de pesquisa e dos pesquisadores e pesquisadoras.

As buscas nas fontes foram realizadas por meio de descritores definidos previamente. A partir da demanda formulada pelo GT Educação da Criança de 0 a 6 anos, iniciamos a pesquisa pelos descritores infância, criança e educação infantil. Em seguida, após a realização de testes com esses descritores, ampliamos os termos de busca com o objetivo de acessar todos os grupos que se ocupam das temáticas relativas a infância, criança e educação infantil registrados no Diretório dos Grupos de Pesquisa no Brasil do CNPq. ${ }^{4}$ Assim,

${ }^{4}$ Um dos limites dessa metodologia refere-se à exclusão dos grupos que não se encontravam registrados no Diretório do acrescentamos: criança de 0 a 6 anos, creche, cultura infantil, pré-escola, educação pré-escolar, infantil e criança pequena.

A análise dos dados buscou estabelecer frequências e percentuais comparativos entre áreas de conhecimento e regiões geográficas para os grupos de pesquisa. Identificou também a incidência da produção da amostra de pesquisadores tomada na pesquisa, estabelecendo correlações que permitiram interpretar elementos da construção da área da infância e educação infantil como campo de pesquisa no Brasil. Os resultados da pesquisa serão apresentados a seguir, de modo que proporcionem uma visão sobre o contexto no qual se inseriam os grupos sobre infância, criança e educação infantil, conforme a seguinte ordem: a) o universo dos grupos de pesquisa no Brasil, considerando todas as áreas do diretório e os totais para cada área da grande área de ciências humanas; b) a apresentação das informações sobre os grupos da área de educação que possuíam linhas de pesquisa sobre educação infantil, criança e infância; c) a apresentação das informações sobre os líderes dos grupos da área de educação que possuíam linhas de pesquisa específicas sobre educação infantil; d) a apresentação das informações sobre a inserção de projetos de pesquisa sobre infância, criança e educação infantil nos programas de pós-graduação em educação constantes do Caderno

$\mathrm{CNPq}$, o que requer outras estratégias de pesquisa. Entre esses grupos encontra-se parte daqueles que, por exemplo, participaram do I Seminário de Grupos de Pesquisa sobre Crianças e Infâncias (GRUPECI), realizado na Universidade Federal de Juiz de Fora (MG), de 25 a 27 de setembro de 2008. Dos 44 grupos que estiveram nesse encontro, apenas 13 foram identificados em nossa primeira busca por grupos da área de educação que pesquisavam infância, criança e educação infantil na base corrente do referido diretório. Dos 31 restantes, somente 7 estão registrados no CNPq, e 4 são da área de educação, 2 da psicologia e 1 da linguística. Nossa busca ocorreu em datas determinadas, o que pode ter sido o motivo para não identificar os grupos da área de educação registrados no CNPq, que podem ter sido temporariamente retirados para atualização ou não apresentaram os descritores típicos. Considerando o total dos grupos, tem-se um percentual de $45 \%$ dos grupos registrados. 
de Indicadores da CAPES referentes à avaliação do triênio 2003-2006.

\section{Grupos de pesquisa registrados no diretório}

Por meio da pesquisa realizada nesse diretório, ${ }^{5}$ identificamos: a) a distribuição dos grupos de pesquisa segundo as grandes áreas de conhecimento a partir do Censo de Grupos de Pesquisa de 2006; ${ }^{6}$ b) a distribuição dos grupos de pesquisa segundo as áreas de conhecimento que compõem a grande área das ciências humanas (Tabela 1); c) o número de grupos de pesquisa registrados em cada área da grande área de ciências humanas, localizados por meio dos descritores mencionados (Tabela 2). Esse conjunto de dados possibilitou inserir os grupos de pesquisa sobre infância, criança e educação infantil no universo dos grupos de pesquisa registrados no diretório do CNPq.

Os grupos de pesquisa registrados na base do CNPq, segundo o Censo de Grupos de Pesquisas de 2006, estavam inicialmente distribuídos pelas oito grandes áreas e, destas, a de ciências humanas foi a que registrou maior número de grupos de pesquisa: 3.679 grupos, perfazendo $17,5 \%$ do total (21.024).

A Tabela 1 apresenta a distribuição dos grupos de pesquisa dentro da grande área de ciências humanas, em que se localiza a educação, de acordo com a tabela de áreas do conhecimento do CNPq. Nela podemos perceber que a educação era a área que concentrava o maior número de grupos de pesquisa

\footnotetext{
${ }^{5}$ Pesquisas realizadas em 29/8, 9/9 e 18/9/2008.
}

${ }^{6}$ Utilizamos os dados do Censo de 2006 e não os da base corrente, mais atualizados, porque é impossível saber, nesta última, o número exato de grupos registrados nas grandes áreas e nas áreas de conhecimento. Conforme classificação do $\mathrm{CNPq}$, essas grandes áreas eram: ciências humanas; ciências da saúde; engenharias e ciência da computação; ciências biológicas; ciências sociais aplicadas; ciências exatas e da terra; ciências agrárias; e lingüística, letras e artes. registrados, com mais de 40\% deles. Esse dado, por sua vez, era coerente com outro levantado junto à CAPES, o qual mostrava que, dentro das ciências humanas, a área de educação era a que tinha o maior número de docentes atuando em programas de pós-graduação do país. Observamos ainda que a segunda área em número de grupos era psicologia; no entanto, possuía um número de grupos quase três vezes menor.

Tabela 1: Distribuição dos grupos de pesquisa por área de conhecimento - ciências humanas

\begin{tabular}{|l|c|c|}
\hline \multicolumn{1}{|c|}{ Área do conhecimento } & Grupos & $\%$ \\
\hline Educação & 1.483 & 40,3 \\
\hline Psicologia & 583 & 14,6 \\
\hline História & 437 & 11,9 \\
\hline Sociologia & 344 & 9,4 \\
\hline Filosofia & 259 & 7,0 \\
\hline Antropologia & 197 & 5,4 \\
\hline Geografia & 185 & 5,0 \\
\hline Ciência política & 152 & 4,1 \\
\hline Teologia & 47 & 1,3 \\
\hline Arqueologia & 37 & 1,0 \\
\hline Total & 3.679 & 100 \\
\hline
\end{tabular}

Fonte: CNPq, Censo dos Grupos de Pesquisa, 2006.

\section{Grupos de pesquisa sobre infância, criança e educação infantil}

Após dimensionar a abrangência e a complexidade da área, passamos a trabalhar apenas com aqueles grupos que, conforme dito anteriormente, foram localizados na base corrente do diretório por meio de indicadores do desenvolvimento de pesquisa a respeito da infância, da criança e da educação infantil: infância, criança, infantil, educação infantil, cultura infantil, creche, pré-escola, pré-escolar, criança de 0 a 6 anos.

Nesse levantamento, de acordo com os dados apresentados na Tabela 2, foram localizados 322 grupos na área de ciências humanas que trabalham com as temáticas acima especificadas. 
Tabela 2: Grupos de pesquisa sobre infância, criança e educação infantil

\begin{tabular}{|l|r|r|r|r|r|r|r|r|r|r|}
\hline \multirow{2}{*}{$\begin{array}{c}\text { Área do } \\
\text { conhecimento }\end{array}$} & \multirow{2}{*}{$\begin{array}{c}\text { Grupos } \\
\mathbf{( 2 0 0 6 )}\end{array}$} & & \multicolumn{10}{|c|}{ Infância } & Infantil & Criança & $\begin{array}{c}\text { Cultura } \\
\text { infantil }\end{array}$ & $\begin{array}{c}\text { Educação } \\
\text { infantil }\end{array}$ & Creche & $\begin{array}{c}\text { Pré- } \\
\text { escolar }\end{array}$ & $\begin{array}{c}\text { Criança } \\
\text { de 0 a 6 } \\
\text { anos }\end{array}$ & Qualquer \\
\hline Educação & 1.483 & 99 & 105 & 39 & 25 & 92 & 6 & 8 & 04 & 182 \\
\hline Psicologia & 538 & 47 & 44 & 42 & 3 & 16 & 5 & 3 & 0 & 105 \\
\hline História & 437 & 10 & 2 & 3 & 0 & 2 & 0 & 0 & 0 & 11 \\
\hline Sociologia & 344 & 12 & 5 & 6 & 1 & 0 & 0 & 0 & 0 & 13 \\
\hline Filosofia & 259 & 1 & 2 & 0 & 0 & 2 & 0 & 0 & 0 & 2 \\
\hline Antropologia & 197 & 5 & 3 & 1 & 2 & 0 & 0 & 0 & 0 & 8 \\
\hline Teologia & 47 & 1 & 0 & 0 & 0 & 0 & 0 & 0 & 0 & 1 \\
\hline Outras* & 837 & 0 & 0 & 0 & 0 & 0 & 0 & 0 & 0 & 0 \\
\hline Total & 3.679 & 175 & 161 & 91 & 31 & 115 & 11 & 11 & 04 & 322 \\
\hline
\end{tabular}

Fonte: CNPq, Censo dos Grupos de Pesquisa, 2006.

* Arqueologia (37), Ciências políticas (152), Geografia (185).

Esses 322 grupos que realizavam pesquisa sobre infância, criança e educação infantil correspondiam a $8,8 \%$ dos 3.679 grupos, que, em 2006, foram registrados como sendo da área de ciências humanas no Censo dos Grupos de Pesquisa. Deles, 182 (56,5\%) estavam na área da educação, e outros 105 (32,6\%) se encontravam na área da psicologia. Como se vê, as outras oito áreas das ciências humanas concentravam apenas $10,9 \%$ dos grupos que trabalhavam sobre as temáticas em apreço, e, nas ciências políticas, na geografia e na arqueologia, não foi localizado um único grupo de pesquisa sobre essas temáticas.

De modo geral, a área de educação era a que apresentava maior número de grupos de pesquisa para quase todos os descritores. A exceção era o descritor criança, para o qual a psicologia apresentava um número de grupos ligeiramente maior do que a educação: 42 contra 39.

$\mathrm{O}$ descritor que mais grupos agregava era infância, com 175 grupos em todas as áreas das ciências humanas (54,3\% dos 322 arrolados). Em seguida, apareciam os descritores infantil (161 grupos, ou 50\% do total), educação infantil (115 grupos, ou 35,7\% do total) e criança (91 grupos, ou 28,3\% do total). Depois, com número bem menor de grupos, vinham os descritores cultura infantil (31 grupos, ou 9,6\% do total), creche e pré-escolar (ambos com 11 grupos ou $3,4 \%$ do total) e, finalmente, educação da criança de
0 a 6 anos, que era o descritor que identificava apenas quatro grupos ( $1,2 \%$ do total). ${ }^{7}$

Desse conjunto de dados, consideramos que merecem destaque os seguintes aspectos: em primeiro lugar, observa-se que a expressão educação infantil parece se ter imposto como uma forma de identificar a educação da criança de 0 até 6 anos. $O$ número de grupos identificados por meio desse descritor era dez vezes maior do que aquele identificado, por exemplo, por meio do descritor pré-escola ou pré-escolar. No entanto, cumpre notar também que a baixa incidência de grupos identificados por meio do descritor creche (11) ou mesmo criança pequena (2 grupos na área da educação) parece indiciar que as pesquisas continuam enfocando sobretudo as crianças (ou o trabalho com as crianças) acima de 3 ou 4 anos. Se nossa hipótese estiver correta, as pesquisas sobre educação infantil continuam priorizando estudos com ou sobre crianças com idade imediatamente anterior à entrada no ensino fundamental.

${ }^{7}$ Observamos que o total dos grupos é menor do que a soma dos grupos localizados para cada descritor. Isso ocorre porque um mesmo grupo pode ser localizado por mais de um dos descritores que utilizamos. Por exemplo, o descritor infantil, que geralmente está associado a alguma outra palavra ou expressão, localiza também, automaticamente, os grupos que utilizam educação infantil e cultura infantil. 
Do mesmo modo, cumpre chamar a atenção para a relativamente alta incidência de grupos localizados a partir do descritor cultura infantil. Como mencionado, são 31 grupos na área de ciências humanas, dos quais $25(80,6 \%)$ estão na área da educação, demarcando claramente que esta é uma temática que ganha corpo no Brasil, sobretudo nos grupos de pesquisa da área de educação.

\section{Grupos de pesquisa sobre infância, criança e educação infantil na área da educação}

Foram identificados, por meio dos descritores indicados, 182 grupos de pesquisa na área da educação. Analisamos as linhas de pesquisa desses grupos para verificar se, de fato, eles investigavam temas relacionados aos descritores citados, tomados aqui como indicadores do desenvolvimento dos temas de pesquisa sobre infância e criança e educação infantil. Após essa pesquisa, verificamos que 32 grupos não apresentavam no título ou nas palavras-chave de suas linhas de pesquisa temas ligados aos descritores. A captura desses grupos na primeira busca deve-se possivelmente à presença de um ou mais termos de busca em algum quadro da descrição do grupo, como área de aplicação, por exemplo. Como não constava nos itens que se referem à descrição do grupo e das linhas de pesquisa do grupo, não foram considerados. Dentre os 150 restantes, verificamos que 70 grupos apresentavam no título ou nas palavras-chave de suas linhas de pesquisa temas específicos da educação infantil (educação infantil, criança de 0 a 6, creche, pré-escola, educação pré-escolar), os quais serão analisados no item relativo aos grupos de pesquisa registrados no Diretório do CNPq, e que os outros 80 grupos apresentavam no título e nas palavras-chave de suas linhas de pesquisa temas ligados a criança ou infância, mas não necessariamente a educação infantil.

A partir dessa base, realizamos uma classificação dos grupos conforme a presença ou não de algum descritor no nome do grupo, no título e nas palavraschave das suas linhas de pesquisa. Consideramos que os grupos que possuíam algum descritor tanto no nome quanto no título e nas palavras-chave das linhas de pesquisa eram os que mais fortemente explicitavam a vinculação com os temas da infância, da criança e da educação infantil. Além disso, identificamos a distribuição dos grupos por regiões do país, considerando a instituição à qual o grupo estava vinculado (Tabela 3).

Tabela 3: Grupos de pesquisa da área da educação sobre infância, criança e educação infantil por região geográfica

\begin{tabular}{|l|c|c|}
\hline \multicolumn{1}{|c|}{ Região } & Freq. & $\%$ \\
\hline Sudeste & 56 & 37,3 \\
\hline Sul & 34 & 22,6 \\
\hline Nordeste & 25 & 16,6 \\
\hline Centro-Oeste & 22 & 14,6 \\
\hline Norte & 13 & 8,6 \\
\hline Total & 150 & 100,0 \\
\hline
\end{tabular}

Fonte: CNPq, Diretório dos grupos de pesquisa.

Pode-se observar que a região que possuía o maior número de grupos era a Sudeste (37,3\%), seguida pela região Sul (22,6\%), concentrando, essas duas, aproximadamente $60 \%$ dos grupos. O Nordeste apresentava $16,6 \%$ dos grupos; o Centro-Oeste, $14,6 \%$; e o Norte, $8,6 \%$.

\section{Temas e tendências de pesquisa}

Com o objetivo de conhecer os temas e tendências de pesquisa dos grupos da área da educação, relacionamos todas as palavras-chave expressas nas linhas de pesquisa dos 150 grupos de pesquisa sobre infância, criança e educação infantil. Foram listadas 864 palavras-chave (palavras ou expressões/temas). Em seguida, realizamos um agrupamento temático para verificar as tendências mais fortes nas linhas de pesquisa desses grupos. Procedemos à análise dos indícios revelados por esses temas considerando todas as palavras-chave com frequência entre 4 e 83. A opção por não incluir as frequências menores que 4 justifica-se pela rarefação revelada por elas. 
A Tabela 4 apresenta a incidência das palavraschave identificadas nos grupos de pesquisa em infância, criança e educação infantil com o objetivo de identificar os temas de pesquisa na área.

Tabela 4: Temas mais frequentes nas palavras-chave das linhas de pesquisa dos grupos de pesquisa em educação infantil, infância e criança

\begin{tabular}{|l|c|}
\hline \multicolumn{1}{|c|}{ Palavras-chave } & Frequência \\
\hline Infância(s) & 83 \\
\hline Educação infantil & 64 \\
\hline Educação & 56 \\
\hline Criança(s) & 38 \\
\hline Formação de professores & 34 \\
\hline Política(s) & 33 \\
\hline Cultura(s) & 28 \\
\hline História; Prática(s) educativa(s) & 17 \\
\hline Brincar & 13 \\
\hline Cultura infantil & 10 \\
\hline Corpo; Desenvolvimento; Formação & 9 \\
\hline $\begin{array}{l}\text { Escola; Gestão; Leitura (leiturização/ } \\
\text { letramento) }\end{array}$ & 8 \\
\hline $\begin{array}{l}\text { Ensino e aprendizagem; Gênero; } \\
\text { Juventude; Violência }\end{array}$ & 7 \\
\hline Interações; Metodologia & 6 \\
\hline $\begin{array}{l}\text { Aprendizagem; Creche; Linguagem; } \\
\text { Ludicidade; Movimentos sociais; } \\
\text { Pedagogia; Sociologia da infância }\end{array}$ & 5 \\
\hline $\begin{array}{l}\text { Alfabetização; Arte; } \\
\text { Desenvolvimento infantil; } \\
\text { Dificuldades de/na aprendizagem; } \\
\text { Direito da criança e do adolescente; } \\
\text { Exclusão; Literatura; Mídia(s); Pré- } \\
\text { escola; Sexualidade }\end{array}$ & \\
\hline Total & 59 \\
\hline
\end{tabular}

Fonte: CNPq, Diretório dos Grupos de Pesquisa no Brasil. Datas de consulta: 29 de agosto de 2009 e 18 de setembro de 2008.

O tema da infância era o mais frequente entre as palavras-chave, seguido pelo tema da educação infantil e da educação de modo geral. As referências às crianças, à formação de professores e às políticas surgiram como os outros três temas mais frequentes.

Esses temas estiveram bastante presentes nos trabalhos apresentados na ANPEd durante toda a existência do GT Educação da Criança de 0 a 6 anos (Rocha, 2008). Os temas seguintes, no que concerne à frequência com que aparecem, marcam também as mudanças conceituais e metodológicas da área a partir dos anos 1990, já que incluem temas referentes à história, à cultura e à cultura infantil, às práticas educativas e ao brincar, evidenciando preocupação com a ampliação das análises. Trabalhos recentes (Rocha, 2008; Silva, 2008) evidenciam que as temáticas, as quais até início dos anos 1990 se centravam nos adultos e nas instituições, passaram a incluir reflexões sobre a ação social das crianças como seres históricos e culturais concretos, reprodutores e produtores de cultura. Essa mudança de foco pode ser relacionada à baixa frequência dos termos creche (5) e pré-escola (4) e à não aparição dos termos professores e educadores de forma isolada. A presença de história corrobora o estudo de Rocha (idem), o qual aponta que, no panorama das investigações produzidas de 1997 a 2004 que resultaram em artigos publicados em periódicos educacionais no Brasil, essa foi a área de cruzamento com a educação que obteve a maior frequência, assim como a sociologia e, mais recentemente, a sociologia da infância, esta última também citada cinco vezes entre as palavraschave dos 150 grupos.

Os demais temas vão ilustrar a variedade de questões e interesses que têm despertado a atenção dos grupos de pesquisa.

\section{Grupos de pesquisa em educação infantil registrados no diretório}

Como já afirmamos, dos 150 grupos de pesquisa que se dedicam aos temas da infância, criança e educação infantil, focalizamos os 70 que explicitavam, no título ou nas palavras-chave de suas linhas, dedicação à pesquisa em educação infantil, ou seja, à educação da criança de 0 a 6 anos de idade, associada ou não a outras temáticas de pesquisa. Esses grupos foram analisados quanto à distribuição por regiões do país. 
Tabela 5: Grupos de pesquisa em educação infantil por região geográfica

\begin{tabular}{|l|c|c|}
\hline \multicolumn{1}{|c|}{ Região } & \multicolumn{2}{c|}{ Grupos } \\
\hline & Freq. & $\%$ \\
\hline Sudeste & 24 & 34,3 \\
\hline Sul & 15 & 21,4 \\
\hline Nordeste & 13 & 18,6 \\
\hline Centro-Oeste & 12 & 17,1 \\
\hline Norte & 6 & 8,6 \\
\hline Total & 70 & 100 \\
\hline
\end{tabular}

Fonte: CNPq, Diretório dos Grupos de Pesquisa, Base corrente.

Na Tabela 5, observa-se que a região que possuía o maior número de grupos de pesquisa em educação infantil registrados no diretório era a Sudeste, com $34,3 \%$, seguida da região Sul, com 21,4\%. Em seguida, vinha a Nordeste, com 18,6\%, seguida da CentroOeste com 17,1\%. Esses percentuais correspondem, com pequenas diferenças, aos percentuais obtidos para cada região quando foram considerados os grupos sobre infância, criança e educação infantil (Tabela 3).

\section{Os pesquisadores na área da educação infantil: líderes de grupos de pesquisa em educação infantil registrados no diretório}

Realizamos uma leitura dos currículos Lattes dos líderes desses grupos, com o objetivo de verificar a formação e a inserção em pesquisas na área. Como as informações constantes dos currículos são passíveis de alteração a qualquer momento e podem não refletir todas as atividades desses/as pesquisadores/as, elas foram interpretadas como indícios da maior ou menor consolidação da educação infantil no conjunto da atuação desses atores em pesquisa. Para essa análise, tomamos como indicadores a presença e a frequência, nos respectivos currículos Lattes, de linhas de pesquisa, projetos de pesquisa, produção bibliográfica e orientação de dissertações de mestrado ou teses de doutorado no período de 2003-2008, cujos títulos/ descrições indicassem a vinculação com temáticas da infância, criança ou educação infantil.

Analisamos também, quanto aos líderes, sexo, titulação, tempo e área de titulação e número desses pesquisadores. Observamos que as pesquisadoras correspondem a $80 \%$ das lideranças dos grupos de pesquisa em educação infantil registrados no diretório. Do total de líderes, $85,7 \%$ possuíam doutorado e $14,3 \%$, somente mestrado. Esses dados revelam a alta qualificação dos pesquisadores e pesquisadoras que coordenavam grupos de pesquisa em educação infantil.

Tabela 6: Líderes de grupos de pesquisa, segundo tempo de titulação

\begin{tabular}{|c|c|c|}
\hline Período Título & \multicolumn{2}{|c|}{$\begin{array}{c}\text { Mestrado ou } \\
\text { doutorado }\end{array}$} \\
\hline & Freq. & $\%$ \\
\hline Até 1990 & 6 & 8,6 \\
\hline 1991 a 1995 & 10 & 14,3 \\
\hline 1996 а 2000 & 21 & 30,0 \\
\hline 2001 a 2005 & 31 & 44,3 \\
\hline A partir de 2006 & 2 & 2,8 \\
\hline Total & 70 & 100 \\
\hline
\end{tabular}

Fonte: CNPq, Plataforma Lattes, set. 2008.

Quanto ao tempo de titulação, observa-se, na Tabela 6, que apenas $8,6 \%$ dos líderes de grupos de pesquisa se titularam até 1990 . Percebe-se que os pesquisadores líderes de grupos de pesquisa em educação infantil se concentravam entre os que se titularam nos últimos oito anos, ou seja, a partir de 2001. Esse dado parece evidenciar que a área se vem tornando objeto do interesse de jovens pesquisadores e pesquisadoras, confirmando a conclusão de Strenzel (2000) na pesquisa relativa ao período de 1983 a 1998.

Parece-nos importante ressaltar também que o período de titulação desses pesquisadores coincide com a consolidação do processo de institucionalização das políticas para a infância e para a educação infantil, bem como com a expansão da pós-graduação no Brasil (Campos, 2002).

Com o objetivo de verificar em que áreas na pós-graduação se desenvolvem pesquisas sobre as temáticas desse estudo, analisamos também a área de titulação dos líderes desses grupos. 
Tabela 7: Líderes de grupos de pesquisa em educação infantil, segundo a área de titulação

\begin{tabular}{|l|c|c|}
\hline \multicolumn{1}{|c|}{ Área de titulação } & Total & $\%$ \\
\hline Educação & 48 & 68,6 \\
\hline Ciências sociais; Antropologia & 07 & 10,0 \\
\hline Psicologia & 06 & 8,6 \\
\hline Filosofia & 02 & 2,85 \\
\hline Ciências do movimento e do esporte & 02 & 2,85 \\
\hline Letras & 02 & 2,85 \\
\hline Artes & 01 & 1,42 \\
\hline História & 01 & 1,42 \\
\hline Linguística & 01 & 1,42 \\
\hline Total & 70 & 100 \\
\hline
\end{tabular}

Fonte: CNPq, Plataforma Lattes, set. 2008.

Observa-se, pelos dados da Tabela 7, que a área predominante de titulação era a educação, com 68,6\%, seguida da área de ciências sociais, com 10\%. A área de psicologia era a terceira em titulação no doutorado, com $8,6 \%$, seguida pelas áreas de filosofia, ciências do movimento/do esporte e letras, com $2,85 \%$ cada uma. E, com $1,42 \%$ dos líderes cada uma, temos as áreas de artes, história e linguística. A maior presença da área de ciências sociais/antropologia, superando inclusive a da psicologia, que tradicionalmente se fez mais presente nas questões relativas à educação infantil, ao lado da educação (Rocha, idem), parece evidenciar a mudança de enfoques teórico-metodológicos que se vem operando na área. Esse dado, associado à presença significativa de palavras-chave como cultura infantil, brincar, história, entre outras, parece indicar a maior presença de perspectivas sociopedagógicas na área. Essa tendência já havia sido identificada por Rocha (idem) no que se refere aos trabalhos mais recentes apresentados no GT Educação da Criança de 0 a 6 anos da ANPEd.

Uma correlação pode ser estabelecida também com o período de titulação de grande parte dos pesquisadores líderes de grupos de pesquisa em educação infantil (Tabela 6), que coincide com o incremento da difusão de abordagens com enfoques antropológicos e sociológicos sobre a infância no Brasil.

$\mathrm{Na}$ Tabela 8 apresentamos a frequência e os percentuais de existência e não existência (possuem/ não possuem) dos itens tomados como indicadores de inserção em pesquisa na área nos currículos Lattes dos líderes de grupos de pesquisa em educação infantil.

Tabela 8: Líderes de grupos de pesquisa, segundo a inserção em pesquisa, produção bibliográfica e orientação de mestrado e doutorado, no período 2003-2008

\begin{tabular}{|l|c|c|c|c|c|c|c|c|}
\hline \multicolumn{2}{r|}{ Atividades } & \multicolumn{2}{r|}{ Linha de pesquisa } & \multicolumn{2}{c|}{ Projeto de pesquisa } & \multicolumn{2}{c|}{$\begin{array}{c}\text { Produção } \\
\text { bibliográfica }\end{array}$} & \multicolumn{2}{c|}{ Orientação concluída } \\
\hline & Freq. & $\%$ & Freq. & $\%$ & Freq. & $\%$ & Freq. & $\%$ \\
\hline Possuem & 21 & $30 \%$ & 30 & $42,8 \%$ & 35 & $50 \%$ & 25 & $35,7 \%$ \\
\hline Não possuem & 49 & $70 \%$ & 40 & $57,2 \%$ & 35 & $50 \%$ & 45 & $64,3 \%$ \\
\hline Total & 70 & $100 \%$ & 70 & $100 \%$ & 70 & $100 \%$ & 70 & $100 \%$ \\
\hline
\end{tabular}

Fonte: CNPq, Plataforma Lattes, set. 2008.

Observamos que, dos líderes dos setenta grupos de pesquisa em educação infantil identificados no diretório, conforme pesquisa realizada em agostosetembro de $2008,70 \%$ não registravam, no Currículo Lattes, linha de pesquisa em educação infantil e 57,2\% não possuíam projetos de pesquisa em educação infantil. Quanto à produção bibliográfica, 50\% não apresentavam nenhuma produção cujo título indicasse a abordagem do tema educação infantil; e 64,3\% não possuíam registro de orientações de dissertações ou teses sobre o mesmo tema no período de 2003 a 2008.

Comparando o número de líderes de grupos de pesquisa que não apresentavam projetos de pesquisa com o número de pesquisadores que possuíam produção bibliográfica, verifica-se que há um percentual maior referente aos que publicaram sobre educação infantil (50\%) do que aqueles que registraram pesquisas sobre o tema $(42,8 \%)$, ou seja, há mais registros 
de publicações na área do que registros de desenvolvimento de projetos de pesquisa.

Quanto à orientação de dissertações de mestrado e teses de doutorado, verifica-se que apenas 35,7\% possuíam orientações sobre educação infantil concluídas no período (2003-2008). Considerando-se que, dos setenta líderes, sessenta são doutores e que somente estes poderiam orientar, o percentual dos que possuíam orientações concluídas no período sobe para 41,7\% (25 em 60).

Para todos os itens considerados - linha de pesquisa, projeto de pesquisa, produção bibliográfica e orientações concluídas -, os resultados revelam que menos de 50\% dos líderes de grupos de pesquisa em educação infantil apresentavam a temática em seus currículos Lattes. Esses dados parecem indicar que a área se vem constituindo por pesquisadores recéminteressados na temática e que há baixa institucionalização da pesquisa na área.

Outro elemento analisado foi a explicitação, no texto de apresentação dos pesquisadores, nos respectivos currículos Lattes, da temática infância ou educação infantil. O pressuposto é de que essa explicitação seja indício da identidade do pesquisador ou da pesquisadora com a área, o que pode significar maiores possibilidades de consolidação da temática. ${ }^{8}$

Dentre os líderes de grupos de pesquisa registrados no diretório, $57,14 \%$ (quarenta) não explicitavam, nos textos de apresentação dos respectivos currículos Lattes, sua atuação na área da infância ou da educação infantil; por sua vez, 42,86\% (trinta) explicitavam atuação profissional ou pesquisa nessas áreas.

Consideramos que essa informação reforça os dados a respeito da inserção na área, os quais parecem revelar que há interesse recente de um conjunto de pesquisadores que, uma vez que a educação infantil

\footnotetext{
${ }^{8}$ Na página inicial de cada currículo, na Plataforma Lattes, há um texto de apresentação gerado automaticamente pelo sistema com base nas informações presentes no currículo ou informado pelo autor. Embora o texto informado pelo autor possivelmente expresse com maior clareza sua vinculação temática, consideramos também os textos gerados automaticamente pelo sistema.
}

se inseriu na educação básica, passaram a encontrar temáticas já desenvolvidas por eles com as questões da infância e da educação infantil. Veremos a seguir que também é muito baixa a presença dos temas infância e educação infantil nos programas de pós-graduação em educação.

\section{A pesquisa sobre infância, criança e educação infantil na pós-graduação brasileira}

Buscando perceber como as temáticas da infância, criança e educação infantil aparecem nas pesquisas desenvolvidas pelos professores dos programas de pós-graduação em educação do país, realizamos um levantamento, utilizando os descritores já apresentados, nos Cadernos de Indicadores relativos ao ano de 2006 (item PP - Projeto de Pesquisa), um dos conjuntos de dados disponibilizados pela CAPES sobre a avaliação dos programas relativa ao triênio 2004-2006. Nossa intenção era identificar quanto a pesquisa institucionalizada na pós-graduação e informada à CAPES abrangeria a área de interesse objeto desta pesquisa.

Em 2006 foram 78 os programas avaliados na área de educação, dos quais $38(48,6 \%)$ se localizavam na região Sudeste, 19 (24,3\%) na região Sul, $11(14,1 \%)$ na região Nordeste, $7(9,3 \%)$ na região Centro-Oeste e $3(3,7 \%)$ na região Norte. A pesquisa nos Cadernos de Indicadores permitiu identificar, na relação de projetos de pesquisa ${ }^{9}$ enviada por todos os programas avaliados em 2006, aqueles que explicitavam alguma relação com as temáticas da infância, da criança e da educação infantil. Aqui também foram utilizados os mesmos descritores de busca (infantil, infância, criança, educação infantil, creche, préescolar e criança de 0 a 6 anos).

A respeito dessa base de dados, é preciso salientar que, de acordo com as regras definidas pela área de

\footnotetext{
9 Em alguns poucos casos, os programas indicavam nessa
} planilha PP (Projeto de Pesquisa) também alguns projetos de extensão. Devido à insignificância estatística destes, embora computados nesta pesquisa, vamo-nos referir a todos como projetos de pesquisa. 
educação na CAPES, é desejável que o docente da pós-graduação esteja envolvido em, no máximo, três projetos de pesquisa. Assim, mesmo que envolvido em maior número projetos, a tendência é de que o pesquisador indique apenas os três considerados por ele como mais importantes, já que o registro de mais projetos para um pesquisador sofre avaliação negativa.
Mencionamos isso para explicitar que é provável que o número de projetos desenvolvidos pelos professores que atuavam nos programas de pós-graduação em educação em 2006 possa ser maior do que aquele informado à CAPES. Foram registrados 2.555 projetos no ano de 2006, abrigados em 301 linhas de pesquisa (Tabela 9).

Tabela 9: Número de programas, linhas e projetos de pesquisa por região (2006)

\begin{tabular}{|c|c|c|c|c|c|c|c|}
\hline \multirow{2}{*}{ Região } & \multirow{2}{*}{$\begin{array}{c}\text { Total de } \\
\text { programas de } \\
\text { pós-graduação }\end{array}$} & \multicolumn{2}{|c|}{ Número total } & \multicolumn{2}{|c|}{ Qualquer descritor } & \multicolumn{2}{|c|}{$\begin{array}{l}\text { Ed. infantil, criança de } \\
0 \text { a } 6 \text { anos, creche, pré- } \\
\text { escola }(r)\end{array}$} \\
\hline & & $\begin{array}{l}\text { Linhas de } \\
\text { pesquisa }\end{array}$ & $\begin{array}{c}\text { Projetos de } \\
\text { pesquisa }\end{array}$ & $\begin{array}{l}\text { Linhas de } \\
\text { pesquisa }\end{array}$ & $\begin{array}{c}\text { Projetos de } \\
\text { pesquisa }\end{array}$ & $\begin{array}{l}\text { Linhas de } \\
\text { pesquisa }\end{array}$ & $\begin{array}{l}\text { Projetos de } \\
\text { pesquisa }\end{array}$ \\
\hline $\begin{array}{l}\text { Centro- } \\
\text { Oeste }\end{array}$ & 7 & 34 & 223 & 0 & 31 & 0 & 11 \\
\hline Nordeste & 11 & 41 & 361 & 1 & 32 & 0 & 12 \\
\hline Sudeste & 38 & 154 & 1.158 & 1 & 156 & 0 & 68 \\
\hline Sul & 19 & 64 & 660 & 1 & 91 & 0 & 39 \\
\hline Norte & 3 & 8 & 53 & 0 & 7 & 0 & 2 \\
\hline Total & 78 & 301 & 2.555 & 3 & 317 & 0 & 132 \\
\hline
\end{tabular}

Fonte: Portal CAPES.

Desse conjunto, foram localizadas por algum dos descritores utilizados, três (1\%) linhas de pesquisa, ou seja, apenas três linhas de pesquisa, entre 301, explicitam em seu título alguma relação com infância, criança ou educação infantil. Esse fato se explica possivelmente em razão de que, nos programas de pós-graduação, diferentemente do que ocorre nos grupos de pesquisa, há maior controle sobre o nome e o escopo das linhas de pesquisa. Isso ajuda a explicar também por que não há nenhuma linha de pesquisa que explicite, no nome, a relação direta com a educação infantil.

Contrastando com os dados relativos às linhas, há um número bastante significativo de projetos que abordam temas relacionados à infância, à criança ou à educação infantil: 317 projetos foram localizados por algum dos descritores utilizados, o que perfaz $12,4 \%$ dos 2.555 projetos registrados. Destes, 132 (5,2\% do total ou 41,6\% dos projetos que investigam infầncia e criança) tratam de algum aspecto relacionado à educação infantil.

Também é significativo observar que em um número pequeno, mas expressivo, de programas não encontramos nenhum projeto identificado pelos descritores, ou seja, havia programas inteiros nos quais não existia registro de qualquer projeto sobre infância, criança ou educação infantil, fato que nos parece extremamente negativo em se tratando da área de educação.

A relação entre os grupos de pesquisa e os programas de pós-graduação em educação encontra-se na Tabela 10.

Tabela 10: Grupos de pesquisa sobre infância, criança e educação infantil e programas de pós-graduação em educação por região

\begin{tabular}{|l|c|c|c|c|}
\hline \multicolumn{1}{|c|}{ Região } & Grupos & $\%$ & Programas & $\%$ \\
\hline Sudeste & 56 & 37,3 & 38 & 48,7 \\
\hline Sul & 34 & 22,6 & 19 & 24,3 \\
\hline Nordeste & 25 & 16,6 & 11 & 14,1 \\
\hline Centro-Oeste & 22 & 14,6 & 7 & 9,0 \\
\hline Norte & 13 & 8,6 & 3 & 3,9 \\
\hline Total & 150 & 100,0 & 78 & 100,0 \\
\hline
\end{tabular}

Fonte: CNPq, Diretório dos Grupos de Pesquisa e Portal CAPES. 
A Tabela 10 evidencia que a distribuição de grupos de pesquisa acompanha o número existente de programas de pós-graduação em educação em cada região do país. As regiões Norte e Nordeste apresentam percentual maior de grupos de pesquisa do que o de programas de pós-graduação, mas ainda assim, comparativamente, ocupam a mesma posição, terceiro e quinto lugares, quando comparadas às demais regiões, tanto em grupos de pesquisa quanto em programas de pós-graduação em educação.

\section{A pesquisa sobre infância, criança e educação infantil no Brasil: considerações finais}

A pesquisa sobre grupos de pesquisa da área de educação que investigavam temas relativos à infância, à criança ou educação infantil em 2008 permitiu verificar que esses grupos estavam presentes em todas as regiões do país. Suas linhas de pesquisa apresentavam grande variedade de assuntos, sinalizando a ampliação do foco das investigações para além de elementos como as instituições, as políticas e os adultos/educadores, que predominaram na produção da área em períodos anteriores. Entretanto, quando analisamos a presença desses grupos no universo dos grupos registrados na grande área das ciências humanas, verificamos que esses temas mobilizam poucos grupos fora das áreas da educação e da psicologia.

As informações sobre os líderes dos setenta grupos que explicitamente investigavam a temática da educação infantil evidenciaram grande presença de pesquisadores jovens, com pouco tempo de titulação. Essa característica é possivelmente um dos fatores que contribuem para a baixa institucionalização das pesquisas da área da educação infantil, conforme pode ser verificado na análise dos programas de pós-graduação e respectivos projetos de pesquisa constantes do Caderno de Indicadores da CAPES.

Além disso, a análise dos currículos dos líderes desses grupos identificou baixa frequência da produção ligada a projetos de pesquisa, o que reforça a hipótese de que boa parte das pesquisas da área da educação infantil esteja sendo realizada sem vincu- lação direta a algum programa de pós-graduação. Essa hipótese pode explicar a discrepância entre os dados encontrados na base corrente do Diretório de Grupos de Pesquisa do CNPq e as informações contidas no Caderno de Indicadores da CAPES. Na base do CNPq foram identificados 150 grupos que investigavam infância, criança e educação infantil, que indicaram 211 linhas de pesquisa sobre esses temas. Nessa divergência devem ser consideradas também as exigências distintas de registro nessas duas bases. O registro de um grupo no CNPq é um processo ágil, que pode ser feito pelo próprio líder, cabendo à instituição somente certificar sua existência. Já o Caderno de Indicadores da CAPES é construído com base nas informações institucionais enviadas pelos programas de pós-graduação, representando a situação das linhas e dos projetos de pesquisa que se supõem estejam efetivamente sendo desenvolvidos.

A análise relativa à produção dos líderes dos setenta grupos que explicitamente investigavam a temática da educação infantil limitou-se à leitura das informações disponibilizadas nos currículos Lattes. Outras informações poderão ser obtidas em uma análise mais aprofundada da produção bibliográfica desses pesquisadores, destacando-se a relevância da investigação sobre os temas de suas teses de doutorado.

Registramos ainda que a partir desse mapeamento são possíveis várias outras análises que deem maior visibilidade às condições da pesquisa sobre infância, criança e educação infantil no Brasil. Dentre estas, salientamos que uma análise da coocorrência das palavras-chave poderá revelar outras tendências da pesquisa sobre esses temas que não se apresentaram neste levantamento inicial. Destacamos também a possibilidade de cruzar as informações aqui levantadas com outros trabalhos que tratem das peculiaridades da pesquisa na graduação e na pósgraduação das instituições de ensino superior do país. Essas análises poderão auxiliar a compreender em que medida a baixa institucionalização da pesquisa sobre educação infantil é uma especificidade dessa área relativamente nova ou se essa situação é fruto 
de outros aspectos mais ligados à própria atividade de pesquisa.

Ressaltamos a necessidade de realização de novos estudos e pesquisas que possam elucidar as razões da existência de um número bastante razoável de grupos de pesquisa em educação infantil, infância e criança e a baixa frequência de linhas de pesquisa na pós-graduação em educação com essas temáticas. Somente com novas investigações será possível elucidar as razões da baixa visibilidade da área da educação infantil na pós-graduação.

Parece-nos também importante realizar pesquisas sobre a produção de conhecimento sobre a infância e as crianças em outras áreas do conhecimento, identificando as abordagens realizadas e suas possíveis contribuições para o emergente campo dos estudos da infância. $\mathrm{O}$ exame das palavras-chave, por exemplo, revelou alta frequência do termo políticas, o que parece expressar a relevância do tema das políticas para infância e para a educação infantil entre os grupos de pesquisa da área da educação. Ao mesmo tempo, constatou-se a inexistência de grupos de pesquisa na área de ciências políticas que apresentassem quaisquer dos descritores utilizados na presente pesquisa.

Investigar os grupos de pesquisa sobre infância, criança e educação infantil no Brasil revelou-se como uma estratégia capaz de evidenciar elementos pouco visíveis no que concerne à constituição da área da educação infantil no campo da educação. Embora as duas últimas décadas se tenham revelado férteis no incremento da pesquisa na área, verificamos que a sua inserção nos programas de pós-graduação ainda é relativamente baixa, remetendo a questões relativas ao lugar da infância e da educação infantil no campo científico em geral e, especificamente, no campo da educação.

\section{Referências bibliográficas}

CAMPOS, Maria Malta. A legislação, as políticas nacionais da educação infantil e a realidade: encontros e desafios: In: MACHADO, Maria Lúcia de A. (Org.). Encontros e desencontros na educação infantil. São Paulo: Cortez, 2002. p. 27-33.
; HADDAD, Lenira. Educação infantil: crescendo e aparecendo. Cadernos de Pesquisa, n. 80, p. 11-20, fev. 1992. ROCHA, Eloisa Acires C. A pedagogia e a educação infantil. Revista Brasileira de Educação, n. 16, p. 27-34, jan./abr. 2001. 30 anos da educação infantil na ANPEd: caminhos da pesquisa. Zero-a-Seis, n. 17, jan./jul. 2008. Disponível em: $<$ http://www.periodicos.ufsc.br/index.php/zeroseis/article/ view/800/6082>.

SILVA, Isabel de Oliveira e. Educação infantil no coração da cidade. São Paulo: Cortez, 2008.

SOBRAL, Fernanda. A. F.; ALMEIDA, Mayra. R. C.; CAIXETA, Marcus. V. C. As lideranças científicas. Ciências \& Cognição, UFRJ, v. 13, n. 2, p. 179-191, jul. 2008.

STRENZEL, Giandréa Reuss. A produção científica sobre educação infantil no Brasil nos programas de pós-graduação em educação.

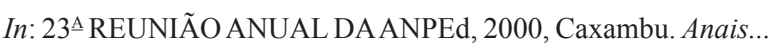
Rio de Janeiro: ANPEd, 2000.

ISABEL DE OLIVEIRA E SILVA, doutora em educação pela Universidade Federal de Minas Gerais (UFMG), é professora do Programa de Pós-Graduação em Educação e pesquisadora do Núcleo de Estudos Infância e Educação Infantil - NEPEI, na mesma instituição. Publicações mais importantes: Educação infantil no coração da cidade (São Paulo: Cortez, 2008); Profissionais da educação infantil: formação e construção de identidades (São Paulo: Cortez, 2003). Pesquisa em andamento: "Cuidar e educar crianças em espaços coletivos: a questão do compartilhamento da socialização das crianças pequenas", com apoio da FAPEMIG e do CNPq.E-mail: isabel.os@uol.com.br

IZA RODRIGUES DA LUZ, doutora em educação pela Universidade Federal de Minas Gerais (UFMG), é professora da Faculdade de Educação e pesquisadora do Núcleo de Estudos Infância e Educação Infantil - NEPEI, na mesma instituição. Publicações mais importantes: Agressividade na primeira infância: um estudo a partir das relações estabelecidas pelas crianças no ambiente familiar e na creche (São Paulo: Cortez, 2008); A agressividade na concepção de Winnicott e suas implicações para a educação infantil (Aprender, v. VI, n. 11, p. 109-137, jul./dez. 2008); Educação infantil: direito reconhecido ou esquecido? (Linhas Críticas, UnB, v. 12, n. 22, p. 41-58, 2006). Pesquisa em andamento: "Função simbólica e agressividade infantil”.E-mail: izaluz@bol.com.br 
Grupos de pesquisa sobre infância, criança e educação infantil no Brasil

LUCIANO MENDES DE FARIA FILHO, doutor em educação pela Universidade de São Paulo (USP), é professor do Programa de Pós-Graduação em Educação da UFMG. Publicações mais importantes: Dos pardieiros aos palácios (Passo Fundo: EdUPF, 2000); organizou 500 anos de educação no Brasil (Belo Horizonte: Autêntica, 2000); Pensadores sociais e história da educação (Belo Horizonte: Autêntica, 2008) e Politicos, literatos, professoras, intelectuais - O debate público sobre educação em Minas Gerais (Belo Horizonte: Mazza, 2009). Desenvolve pesquisas na área de história da educação e história da infância com o apoio do CNPq e da FAPEMIG. E-mail: lucianom@ufmg.br

Recebido em fevereiro de 2009 Aprovado em outubro de 2009 
Isabel de Oliveira e Silva, Iza Rodrigues da Luz e Luciano Mendes de Faria Filho

Grupos de pesquisa sobre infância, criança e educação infantil no Brasil: primeiras aproximações

$\mathrm{O}$ artigo apresenta um mapeamento dos grupos e instituições que produzem pesquisas na área de educação sobre a infância, a criança e a educação infantil no Brasil, por regiões geográficas e principais temas investigados. Para o desenvolvimento da pesquisa, procedeu-se a consultas no Diretório de Grupos de Pesquisa do CNPq, nos Cadernos de Indicadores dos Programas de Pós Graduação em Educação, relativos ao ano de 2006, e na base Lattes do CNPq.

Palavras-chave: educação infantil; infância; criança; grupos de pesquisa.

\section{Research groups on infancy,} children and preschool education in Brazil: first approaches

The article presents a survey of groups and institutions which produce research in the field of education on infancy, children and preschool education in Brazil by geographical regions and principal themes investigated. In order to carry out the research the CNPq Directory of Research Groups was consulted as were the Notebooks of Indicators of Postgraduate Programmes in Education, with relation to 2006 and the $C N P q$

Lattes data base.

Key words: preschool education; infancy; children; research groups.

Los grupos de pesquisa sobre la infancia, niños y educación infantil en Brasil: primeras aproximaciones El artículo presenta un registro de los grupos e instituciones que producen pesquisas en el área de educación sobre la infancia, el niño y la educación infantil en Brasil, por regiones geográficas y principales temas investigados. Para el desarrollo de la pesquisa se procedió a consultas en el Directorio de Grupos de Pesquisa del CNPq, en los Cuadernos de Indicadores de los Programas de Postgrado en Educación, relativos al año de 2006, y en la base Lattes del CNPq.

Palabras claves: educación infantil; infancia; niño; grupos de pesquisa. 